\title{
Breast ultrasound in the management of gynecomastia in Peutz-Jeghers syndrome in monozygotic twins: two case reports
}

\author{
Graziella Di Grezia ${ }^{1 *}$, Tiziana Romano ${ }^{2}$, Francesco De Francesco ${ }^{3}$, Francesco Somma ${ }^{1}$, Gaetano Rea ${ }^{4}$, Roberto Grassi ${ }^{1}$ \\ and Gianluca Gatta'
}

\begin{abstract}
Introduction: Peutz-Jeghers syndrome is an autosomal dominant disease with incomplete penetrance and variable expression caused by germline mutation of serine threonine kinase 11/liver kinase B1; it is characterized by hamartomatous polyps in the gastrointestinal tract, mucocutaneous melanin pigmentation, and increased predisposition to neoplasms. In Peutz-Jeghers syndrome, bilateral Sertoli cell testicular tumors cause endocrine manifestations including gynecomastia and feminization.

This study aimed to assess the role of breast ultrasound in the evaluation of the effectiveness of an innovative surgical approach.
\end{abstract}

Case presentation: This report presents a pair of European 9-year-old identical male twins with Peutz-Jeghers syndrome, bilateral prepubertal gynecomastia, and testicular multifocal calcifications. Both twins were treated with anastrozole for 2 years. After finishing treatment, both underwent subcutaneous mastectomy performed by the "modified" Webster technique. Breast examination and ultrasound were performed before and after the pharmacological and surgical treatment. A breast ultrasound scan before surgery showed bilateral gynecomastia in both patients. No solid nodular or cystic formations were present on either side. After pharmacological therapy and surgical glandular removal, a breast examination showed a significant reduction in breast volume; 1 year after surgery, a breast ultrasound scan of both patients showed a total absence of glandular parenchyma, with muscle planes well represented.

Conclusions: Breast examination and ultrasound have proved to be a valid approach in the assessment of the treatment of prepubertal gynecomastia because they allow the efficacy of the pharmacological and surgical treatment to be evaluated in a multidisciplinary approach to one of the most frequent endocrine manifestations of Peutz-Jeghers syndrome.

Keywords: Breast ultrasound, Gynecomastia, Peutz-Jeghers, Subcutaneous mastectomy

\section{Introduction}

Peutz-Jeghers syndrome (PJS) is an autosomal dominant disease with incomplete penetrance and variable expression $[1,2]$ caused by germline mutation of serine threonine kinase 11 (STK11/liver kinase B1, LKB1) [3,4].

It is characterized by increased predisposition to neoplasms [5] and hamartomatous polyps in the gastrointestinal tract, and mucocutaneous melanin pigmentation with

\footnotetext{
*Correspondence: graziella.digrezia@libero.it

'Department of Clinical and Experimental Medicine "F. Magrassi, A. Lanzara", Section of Radiology and Radiotherapy, Second University of Naples, Naples, Italy

Full list of author information is available at the end of the article
}

high phenotypic variability. In PJS, high aromatase activity [6] causes oversecretion of estrogen by bilateral Sertoli cell testicular tumors (large-cell calcifying tumors) with advanced bone age, feminization and gynecomastia.

Gynecomastia is a benign condition characterized by enlargement of the male breast due to proliferation of glandular tissue; it is common in normal males during the neonatal period, at early puberty, and with increasing age. Prepubertal gynecomastia is characterized by the presence of palpable uni- or bilateral breast tissue in boys without other signs of sexual maturation. It could be related with excessive estrogen production by adrenal or testicular 
tumors [7-9], also in rare syndromes such as PJS, congenital adrenal hyperplasia, or overexpression of aromatase or to the use of drugs that affect androgen and estrogen production and metabolism. This case report describes the role of breast ultrasound in the surgical management of prepubertal gynecomastia and subsequent follow-up in monozygotic twins with PJS and bilateral multifocal testicular calcifications.

\section{Case presentation}

A pair of European 9-year-old identical male twins (patients 1 and 2) with PJS presented with bilateral progressive prepubertal gynecomastia over the course of 1 year. The family history showed that their father had PJS but no history of gynecomastia or testicular calcification. Neither mutations nor deletions where found in the tumor suppressor gene LKB1/STK11, which is responsible for approximately $60 \%$ of PJS cases.

The twins arrived at our Department in 2008. A physical examination showed two boys with pigmented lesions of the lips and bilateral gynecomastia with a diameter of $9 \mathrm{~cm}$ in patient 1 and $7 \mathrm{~cm}$ in patient 2 , corresponding to a female Tanner stage B3. Their testicular volume was $4 \mathrm{~mL}$ bilaterally. The boys' penises were infantile, and they had no pubic or axillary hair (pubic hair, PH1; genitalia development, G1).

The height of patient 1 was $129.2 \mathrm{~cm}$ (25th percentile), with a growth velocity of $7 \mathrm{~cm}$ /year (90th percentile for age) and normal weight for height. The height of patient 2 was $125.5 \mathrm{~cm}$ (10 to 25 th percentile), with a growth velocity of $6 \mathrm{~cm} /$ year (75 to 90th percentile) and normal weight for height. The target height was $173 \mathrm{~cm}(-0.7$ Standard Deviation Score, SDS).

\section{Hormonal treatment}

Hematic levels of sexual hormones were constantly verified with specific reference to luteinizing hormone (LH), follicle-stimulating hormone (FSH), prolactin, testosterone, estrone and estradiol.

Baseline endocrine investigations in patients 1 and 2 showed normal prepubertal serum concentrations of testosterone, FSH, LH and dehydroepiandrosterone sulfate, as well as slightly elevated levels of estradiol, with normal levels of estrone.

Both boys were treated with the third-generation aromatase inhibitor, anastrozole, starting dose of $1 \mathrm{mg}$ orally once daily. The decision to treat the boys with the aromatase inhibitor anastrozole had been implemented to reduce gynecomastia and to prevent the accelerating effect of estrogen excess on skeletal maturation.

Samples were obtained before the beginning of the anastrozole treatment, then after 1 and 2 years of treatment, during 2-years follow-up evaluation, before and after 3 months subcutaneous mastectomy surgery.

During the period of anastrozole treatment, a reduction of gynecomastia was observed more in one twin than in the other. In particular, during the first year of treatment, growth velocity decreased from 7 to $3 \mathrm{~cm}$ and gynecomastia decreased from 9 to $4 \mathrm{~cm}$ in diameter in patient 1 , whereas growth velocity decreased from 6.6 to $3 \mathrm{~cm} /$ year and gynecomastia decreased from 7 to $3 \mathrm{~cm}$ in diameter in patient 2.

During the second year of treatment, no changes in gynecomastia occurred, and growth velocity reverted to normal values for age in patient $1(5 \mathrm{~cm} /$ year $)$, whereas it remained below the normal value for age in patient 2 $(3.5 \mathrm{~cm} /$ year $)$.

After 2 years, a sharp reduction in growth velocity occurred for both patients (although it was more pronounced in patient 2 , with a growth velocity of $1.6 \mathrm{~cm} /$ year, $3 \mathrm{rd}$ percentile), which prompted a reduction in the anastrozole dose and then its withdrawal at the age of 11.5 years.

After a washout period of 6 months, clinical reevaluation of both twins showed regrowth of gynecomastia, corresponding to a female Tanner stage B3, with resumed tenderness of the breast to palpation (Table 1, Figure 1).

\section{Bone age}

To determine bone age, X-rays of each patient's nondominant hand and wrist were analyzed by the TW2 method before anastrozole treatment was started, and after 1 year of treatment and 2 years of treatment.

Table 1 Breast ultrasound monitoring of gynecomastia and growth before treatment (enrollment), during 2 years of pharmacological treatment (first and second year), at pharmacological interruption ( $>2$ years), and before and after surgical removal

\begin{tabular}{|c|c|c|c|c|c|c|c|c|}
\hline & & \multirow[t]{2}{*}{ Enrollment } & \multicolumn{2}{|c|}{ Pharmacological treatment } & \multirow{2}{*}{$\begin{array}{c}\text { Pharmacological } \\
\text { interruption } \\
>2 \text { years }\end{array}$} & \multirow{2}{*}{$\begin{array}{c}\text { Before } \\
\text { surgery } \\
2 \text { years } \\
6 \text { months }\end{array}$} & \multirow{2}{*}{$\begin{array}{c}1 \text { month after } \\
\text { surgery }\end{array}$} & \multirow{2}{*}{$\begin{array}{l}1 \text { year after } \\
\text { surgery }\end{array}$} \\
\hline & & & First year & Second year & & & & \\
\hline \multirow[t]{2}{*}{ Breast growth (cm/year) } & Patient 1 & 7 & 3 & 5 & 5 & 6 & 0 & 0 \\
\hline & Patient 2 & 6.6 & 3 & 3.5 & 1.6 & 3.6 & 0 & 0 \\
\hline \multirow[t]{2}{*}{ Gynecomastia $(\mathrm{cm})$} & Patient 1 & 9 & 4 & 4 & 4 & 5 & 0 & 0 \\
\hline & Patient 2 & 7 & 3 & 3 & 3 & 6 & 0 & 0 \\
\hline
\end{tabular}




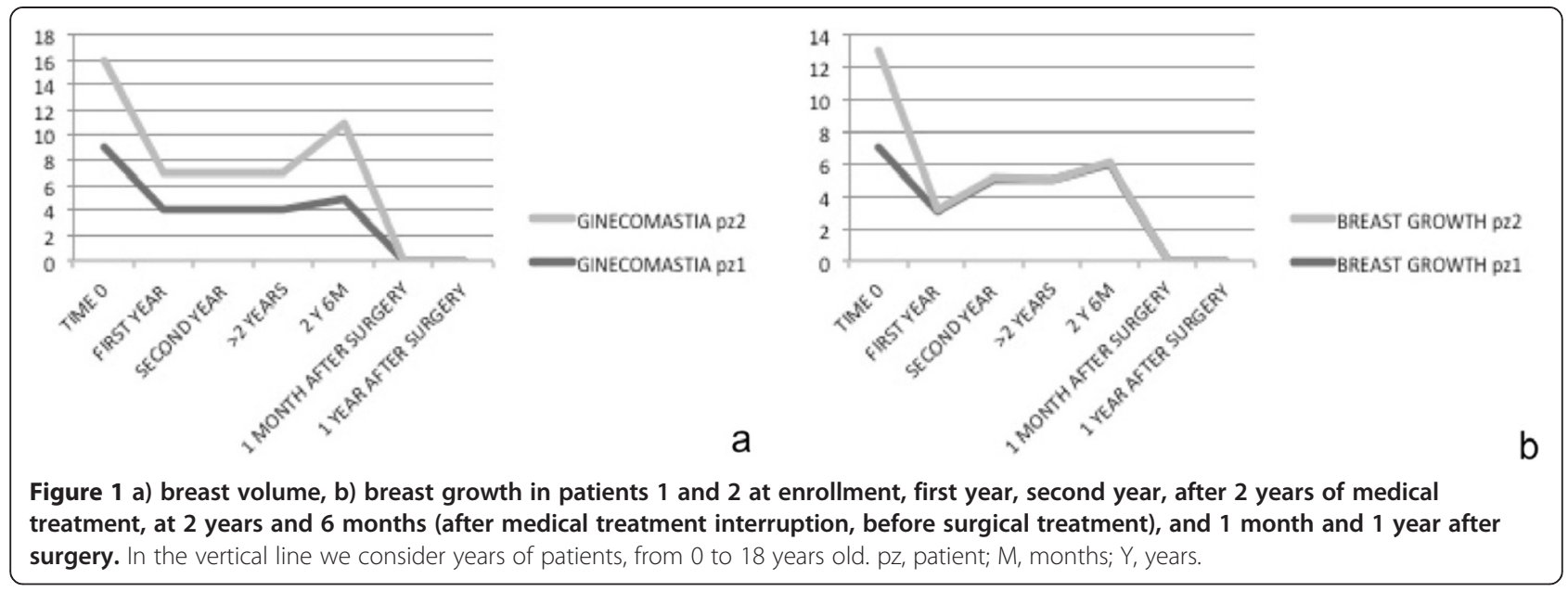

Bone age was 11.2 years in patient 1 and 10.9 years in patient 2, with an advance of approximately 2.5 years and an adult height prognosis of $157 \mathrm{~cm}$ (-3 SDS) for patient 1 and $158.7 \mathrm{~cm}(-2.8$ SDS) for patient 2 (both below the target height).

\section{Ultrasound findings}

Ultrasound was performed using a Logiq S6 scanner (GE Healthcare, Waukesha, WI, USA) with a multifrequency matrix-array linear transducer ( 7 to $14 \mathrm{MHz}$ ) and a multifrequency convex transducer ( 3.5 to $5 \mathrm{Mhz}$ ).

A breast ultrasound to assess palpable masses was performed during and after pharmacological treatment, before and after 1 month and 1 year from subcutaneous mastectomy surgery. The examinations showed bilateral gynecomastia with typical hyperechoic fibroglandular tissue. No solid nodular or cystic formations were present on either side.

An abdominal ultrasound scan of their adrenal glands and a testicular ultrasound scan were performed to analyze the presence of estrogen-producing adrenal tumor; a testicular ultrasound scan showed bilateral multifocal calcifications.

\section{Surgical treatment}

At the age of 13 years, the twins underwent gynecomastia surgical treatment, using the Webster technique. A skin incision was made below the areola edge and the adipose and glandular tissues were significantly removed under direct vision from the skin at the top and from the pectoral muscle at the bottom; the removed breast tissue was sent to a pathologist.

The result was radical surgery (thus avoiding recurrence) and a good aesthetic result.

In both boys, an advancement flap of adipose tissue below the nipple-areola complex was placed, in consideration of the underlying disorder, to avoid leaving a residual subareolar glandular parenchyma (Figures 2 and 3).

Although the glandular tissue had been completely removed, this technique allowed a good aesthetic result, thus avoiding depression of the nipple-areola complex, which would remain responsive to the circulating estrogen.
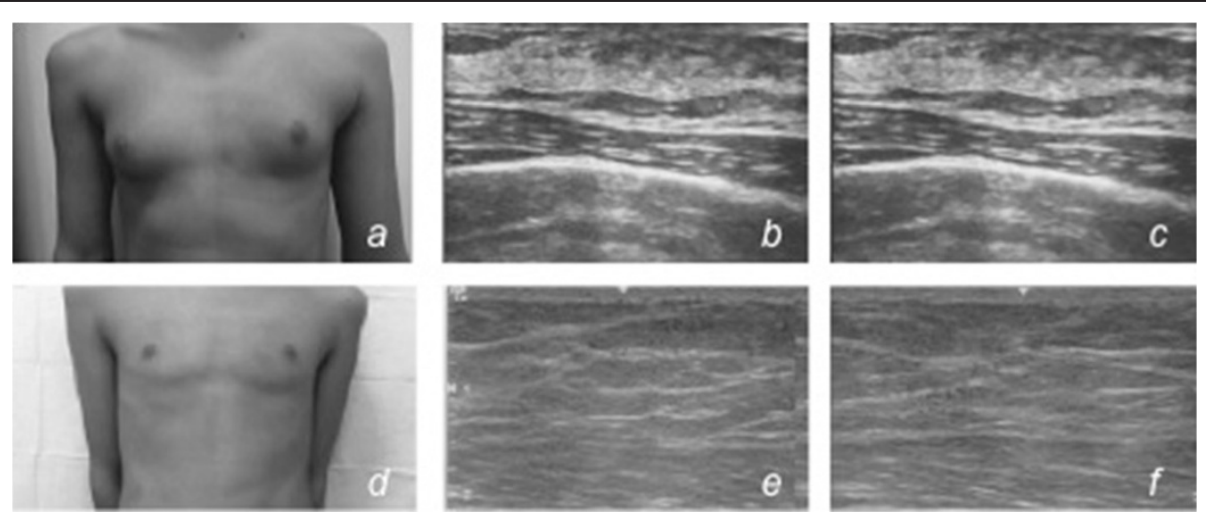

Figure 2 Patient 1. Clinical preoperative breast view (a) and breast ultrasound $(\mathbf{b}, \mathbf{c})$ scan showing bilateral gynecomastia. No solid nodular or cystic formations are present on either side; clinical postoperative breast view (d) and breast ultrasound (e,f) scan 1 year after surgery showing a total absence of glandular parenchyma, with muscle planes well represented. 

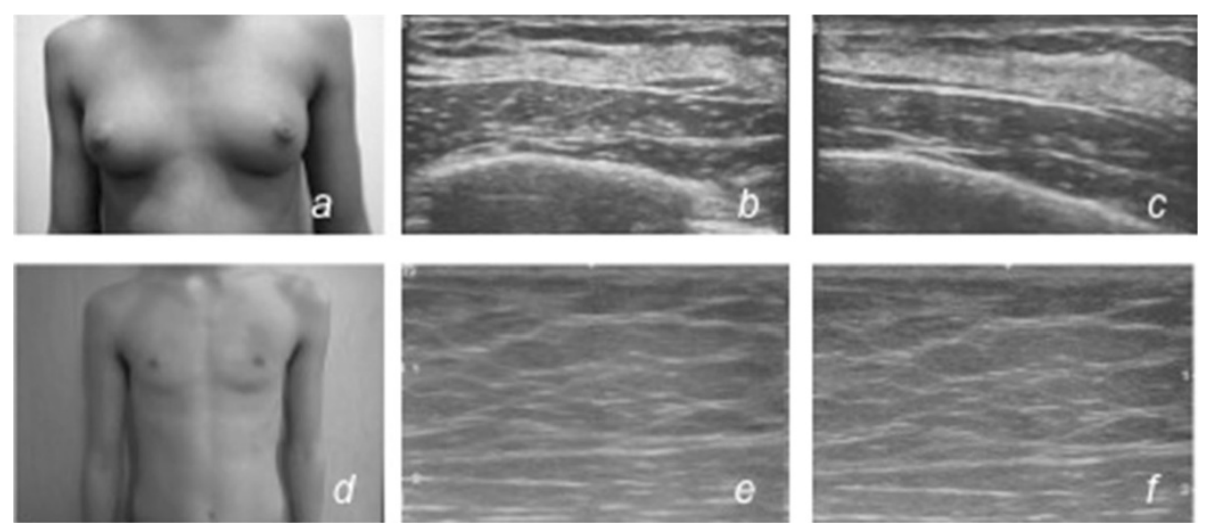

Figure 3 Patient 2. Clinical preoperative breast view (a) and breast ultrasound $(\mathbf{b}, \mathbf{c})$ scan showing bilateral gynecomastia. No solid nodular or cystic formations are present on either side; clinical postoperative breast view (d) and breast ultrasound (e,f) scan 1 year after surgery showing a total absence of glandular parenchyma, with muscle planes well represented.

Both patients were satisfied with the result and had no functional impairment of their arms or reduction in nipple-areola complex sensitivity. Wound healing was completed in 10 days, and scars were almost undetectable in both cases. The excessive removal of parenchyma did not result in skin irregularities, avoiding any unnecessary subsequent treatment. Both patients received postoperative pain management with painkillers according to their weight. The clinical course had no irregularities. No surgical infections or hematomas were reported. Although the breast gland had been totally removed, both patients had good cutaneous retraction and no nipple or areola necrosis or deformity, as confirmed by ultrasound picture control.

Histologic findings confirmed their condition to be benign. After surgical glandular removal, a breast examination showed a significant reduction in breast volume; 1 year after surgery, a breast ultrasound scan of both patients showed a total absence of glandular parenchyma, with muscle planes well represented.

A compressive medication was applied after surgery with a chest bandage for 4 weeks.

Analgesics were prescribed only in case of pain. Both boys were observed by surgeons 1 and 4 weeks after surgery for removal of the bandage and to exclude the onset of hematomas, seromas, skin infections, keloids and pain.

\section{Follow-up}

After surgery, the twins were followed for an additional year for evaluation of sex hormone levels, growth curve and breast size.

\section{Discussion}

Gynecomastia is a multifactorial disease, primarily dependent on the balance between free estradiol and free testosterone. Estrogen biosynthesis results from the production of androgens from steroid precursors; therefore, an excess of endogenous estrogen can be a result of an increase in substrate, aromatase activity, or both.

An increase in the level of estrogen is the most common cause of imbalance. The most common causes of gynecomastia are endocrinopathies, neoplasm-producing estrogens, human chorionic gonadotropin or aromatase, hyperaromatase syndrome [6] and only few cases of idiopathic prepubertal disease. The frequencies of some remaining causes have been estimated as follows: cirrhosis $(8 \%)$, primary hypogonadism $(8 \%)$, testicular tumors (3\%), secondary hypogonadism (2\%), hyperthyroidism $(1.5 \%)$, and renal disease (1\%).

Testicular cancer (associated with both germ cell tumors and non-germ cell tumors) accounts for 1 to $1.5 \%$ of all male neoplasms. Although PJS represents one of the genetic conditions predisposing to these types of tumors, it remains a rare condition [10-13]. Our two patients with PJS with large-cell calcifying Sertoli cell tumors had prepubertal gynecomastia for approximately 1 year (Tanner stage 3) and had advanced bone age from the increased level of serum estradiol.

The treatment of prepubertal gynecomastia depends on its etiology. Medical therapy with an aromatase inhibitor alone is not effective in reversing prepubertal gynecomastia. The initial florid stage, characterized by ductal proliferation, can respond to medical treatment but, subsequently, glandular hyperplasia is replaced by progressive fibrosis and hyalinization; when it causes painful or psychological disturbance, surgical removal of the breast glandular tissue is indicated $[10,14]$.

However, anastrozole represents the first noninvasive step of treatment in PJS and may be useful for delaying surgery in very young patients to achieve an optimal aesthetic result. Plastic surgeons used a standard mastectomy through a semicircular incision within the margin of the pigmented area of the areola to conceal the scar. 
The standard technique included positioning a 5- to 7$\mathrm{mm}$ pad under the nipple to prevent dermal adherence to the pectoralis fascia. To prevent possible recurrence, they totally removed the gland and set up an advancement flap of adipose tissue to prevent adhesion of the nipple to the pectoralis fascia and its unaesthetic depression.

In conclusion, gynecomastia is a multifactorial disorder, and a correct evaluation must be performed to distinguish physiologic and pathologic causes. The history must include testicular assessment symptoms of hepatic disease and alcohol consumption as well as family history. Physical examination and a routine biochemical profile permit an acknowledgement and recognition of most underlying causes.

\section{Conclusions}

Although severe gynecomastia is a rare condition in the pediatric age, competence and expertise is necessary for the treatment of these patients. Breast examination and ultrasound have proved to be a valid approach in the assessment of the treatment of prepubertal gynecomastia because they allow the efficacy of the pharmacological and surgical treatment to be evaluated in a multidisciplinary approach to one of the most frequent endocrine manifestations of PJS.

\section{Consent}

Written informed consent was obtained from the patients' mother for publication of this case report and accompanying images. A copy of the written consent is available for review by the Editor-in-Chief of this journal.

\section{Abbreviations \\ FSH: Follicle-stimulating hormone; LH: Luteinizing hormone; PJS: Peutz-Jeghers syndrome; SDS: Standard Deviation Score.}

\section{Competing interests}

The authors declare that they have no competing interests.

\section{Authors' contributions}

GDG made substantial contributions to conception and design; TR made substantial contributions to acquisition of data, FDF made substantial contributions to analysis of data, FS agrees to be accountable for all aspects of the work in ensuring that questions related to the accuracy or integrity of any part of the work are appropriately investigated and resolved, GR made substantial contributions to interpretation of data, RG gave final approval of the version to be published, GG has been involved in drafting the manuscript or revising it critically for important intellectual content. All authors read and approved the final manuscript.

\section{Acknowledgement}

We are greatly indebted to Silvia Losco for language consultancy.

\section{Author details}

'Department of Clinical and Experimental Medicine "F. Magrassi, A. Lanzara", Section of Radiology and Radiotherapy, Second University of Naples, Naples, Italy. ${ }^{2}$ Pediatric Department, Second University of Naples, Naples, Italy.

${ }^{3}$ Department of Orthopedic, Traumatologic, Rehabilitative, and Plastic-Reconstructive Sciences, Second University of Naples, Naples, Italy. ${ }^{4}$ Radiology Department, Monaldi Hospital, Ospedale dei Colli, Naples, Italy.
Received: 4 March 2014 Accepted: 6 October 2014

Published: 18 December 2014

\section{References}

1. Cl A, Bali D, Thiel TJ, Anderson JP, Gourley I, Frazier ML, Lynch PM, Luchtefeld MA, Young A, McGarrity TJ, Seldin MF: Fine mapping of a genetic locus for Peutz-Jeghers syndrome on chromosome 19p. Cancer Res 1997, 57:3653-3656.

2. Hemminki $A$, Tomlinson I, Markie $D$, Järvinen $H$, Sistonen $P$, Björkqvist $A M$, Knuutila S, Salovaara R, Bodmer W, Shibata D, De la Chapelle A, Aaltonen LA: Localization of a susceptibility locus for Peutz-Jeghers syndrome to $19 p$ using comparative genomic hybridization and targeted linkage analysis. Nat Genet 1997, 15:87-90.

3. Jenne DE, Reimann H, Nezu J, Friedel W, Loff S, Jeschke R, Müller O, Back W, Zimmer M: Peutz-Jeghers syndrome is caused by mutations in a novel serine threonine kinase. Nat Genet 1998, 18:38-43.

4. Jiang CY, Esufali S, Berk T, Gallinger S, Cohen Z, Tobi M, Redston M, Bapat B: STK11/LKB1 germline mutations are not identified in most Peutz-Jeghers syndrome patients. Clin Genet 1999, 56:136-141.

5. Giardiello FM, Trimbath JD: Peutz-Jeghers syndrome and management recommendations. Clin Gastroenterol Hepatol 2006, 4:408-415.

6. Bulun SE, Noble LS, Takayama K, Michael MD, Agarwal V, Fisher C, Zhao Y, Hinshelwood MM, Ito Y, Simpson ER: Endocrine disorders associated with inappropriately high aromatase expression. J Steroid Biochem Mol Biol 1997, 61:133-139.

7. Itami RM, Amundson GM, Kaplan SA, Lippe BM: Prepubertal gynecomastia caused by an adrenal tumor. Diagnostic value of ultrasonography. Am J Dis Child 1982, 136:584-586.

8. Coen P, Kulin H, Ballantine T, Frauenhoffer E, Boal D, Inkster S, Brodie A, Santen R: An aromatase-producing sex-cord tumor resulting in prepubertal gynecomastia. N Engl J Med 1991, 324:317-322

9. Berensztein E, Belgorosky A, de Davila MT, Rivarola MA: Testicular steroid biosynthesis in a boy with a large cell calcifying Sertoli cell tumor producing prepubertal gynecomastia. Steroids 1995, 60:220-225.

10. Kara C, Kutlu AO, Tosun MS, Apaydin S, Senel F: Sertoli cell tumor causing prepubertal gynecomastia in a boy with Peutz-Jeghers syndrome: the outcome of 1-year treatment with the aromatase inhibitor testolactone. Horm Res 2005, 63:252-256.

11. Gourgari E, Saloustros E, Stratakis CA: Large-cell calcifying Sertoli cell tumors of the testes in pediatrics. Curr Opin Pediatr 2012, 24:518-522. Aesth Plast Surg.

12. Esposito V, Gatta G, Di Grezia G, lacomino A, Fiumarella A, Russo A, Feragalli B, Grassi R: Anatomical features of cephalothoracopagus variations: $C T$ and MRI. J Biol Regul Homeost Agents 2013, 27(2):595-602

13. Ferraro GA, Romano T, De Francesco F, Grandone A, D'Andrea F, Miraglia del Giudice E, Cataldo C, Gatta G, Di Grezia G, Perrone L, Nicoletti G: Management of prepubertal gynecomastia in two monozygotic twins with Peutz-Jeghers syndrome: from aromatase inhibitors to subcutaneous mastectomy. Aesth Plast Surg 2013, 37(5):1012-1022.

14. Devalia HL, Layer GT: Current concepts in gynaecomastia. Surgeon 2009, 7:114-119.

\section{doi:10.1186/1752-1947-8-440}

Cite this article as: Di Grezia et al:: Breast ultrasound in the management of gynecomastia in Peutz-Jeghers syndrome in monozygotic twins: two case reports. Journal of Medical Case Reports 2014 8:440. 